\title{
Analysis of a feller-buncher productivity: a case study of whole-tree harvesting from Marmara region, Turkey
}

\author{
Neșe Gülci ${ }^{\circledR}$, Kıvanç Yüksel', Sercan Gülci', Hasan Serin', Ebru Bilici², Abdullah E. Akay³
}

Gülci N., Yüksel K., Gülci S., Serin H., Bilici E., Akay A.E., 2021. Analysis of a feller-buncher productivity: a case study of whole-tree harvesting from Marmara region, Turkey. Ann. For. Res. 64(1): 99-110.

Abstract In fully mechanized forest harvesting systems, tree felling activities are mostly performed by using harvesters or feller-bunchers. In some regions of Turkey, where terrain conditions and stand characteristics are suitable, fully mechanized harvesting systems have been recently practiced by some of the logging contractors as private forest industry demands for large amounts of forest products throughout the year. Thus, performances of these newly practiced harvesting systems should be carefully analyzed in order to implement productive and cost-effective mechanized harvesting systems. In this study, productivity of whole-tree harvesting using a feller-buncher was investigated based on stand parameters including tree height, $\mathrm{DBH}$, and volume. The DBH of the felled trees were divided into four classes (i.e. very small: $16-19 \mathrm{~cm}$, small: $20-23 \mathrm{~cm}$, medium: $24-27 \mathrm{~cm}$ and large: $28-31$ $\mathrm{cm})$ to investigate the effects of various DBH class on the time consumption of cutting stage and productivity of the feller-buncher. To estimate productivity of feller-buncher in harvesting operation, multiple linear and polynomial regressions were also developed and discussed after the interpretation of diagnostic plots. The results indicated that the average productivity of the feller-buncher was $74.96 \mathrm{~m}^{3} / \mathrm{h}$ which was closely related with tree height $(r=0.63)$, DBH $(r=0.67)$, and volume $(r=0.67)$. The average moving time was the most time-consuming stage $(60 \%)$, followed by cutting $(29 \%)$ and bunching stages $(11 \%)$. It was found that DBH classes caused statistically significant $(p<0.05)$ effects on the time spent on cutting stage and productivity of the feller-buncher. The cutting time and productivity increased from very small to large diameter classes, while bunching time increased from very small to small diameter and then medium diameter to large diameter classes. Polynomial regression had a positive impact on the performance of the estimation model of manually field-measured data based on the error parameters.

Keywords: clear cutting, mechanized harvesting, quadratic model, statistical analysis.

Addresses: ${ }^{1}$ Faculty of Forestry, Kahramanmaras Sutcu Imam University, Turkey.| ${ }^{2}$ Dereli Vocational School, Forestry Program, Giresun University, Turkey. ${ }^{3}$ Faculty of Forestry, Bursa Technical University, Bursa, Turkey.

$\square$ Corresponding Author: Neşe Gülci (nesegulci@gmail.com).

Manuscript received September 25, 2020; revised May 18, 2021; accepted June 24, 2021. 


\section{Introduction}

Due to recent developments in climate change measures and energy security policies, both forest officers and harvesting contractors need to search for the optimum methods and machine combinations for suitable forest harvesting operations while considering the best management practices. The harvesting operations taking place in the production of wood-based forest products are subject to key restrictions such as technical, economic, environmental and ergonomic ones. Due to increasing global demands on woody biomass throughout the whole year, private forest industry aims to produce large amount of wood products by the means of mechanized harvesting systems while considering the best productivity goals (Swezy et al. 2021). When the production stages of forest biomass, which is demanded as clean energy, are conducted at low cost, the demanded forest biomass cost will decrease accordingly. Thus, operational optimization should be carried out at strategic, tactical and operational levels of forest harvesting (Acuna et al. 2019).

Forest harvesting involves several activities including tree felling, delimbing, bucking, extraction, loading, and hauling (Eker \& Acar 2006, Akay et al. 2010, Gülci et al. 2017). The methods implemented during forest harvesting are cut-to-length, tree-length and whole-tree methods (Öztürk 2006, Erler et al. 2012, Erdaş et al. 2014, Gülci 2014). The most common one is cut-to-length method because it is compatible with all the harvesting techniques such as mechanized harvesting, manual harvesting, skidding, forwarding, cable logging, etc. In Turkey, cut-to-length is also the most common method in forest harvesting which is mainly conducted by manual techniques while the use of mechanized harvesting is limited. However, mechanized harvesting equipment (i.e. harvester, feller-buncher and skidder) has been recently used in some regions of Turkey where private forest industry continuously demands for large amounts of wood-based products (Bilici et al. 2018).

When dealing with new harvesting equipment, forest harvesting operations should be well understood and planned based on accurate estimation of equipment productivity. Otherwise, mechanized harvesting operations can be very costly activities. In countries with long mechanized harvesting history, the productivity, cost and performance of harvesting equipment has been studied extensively (Nurminen et al. 2006, Hiesl \& Benjamin 2013, Abbas et al. 2014, Apăfãian et al. 2017, Fernandez-Lacruz et al. 2020). However, there are very limited studies that analyzed the performance of mechanized harvesting equipment in Turkey. Enez \& Arıcak (2012) evaluated the performance of a Volvo harvester which was the first harvester operated in Turkey. Then, Bilici \& Abbas (2018) investigated the productivity of Doosan DX 3001C harvester used in a post-fire salvage harvesting operations in the city of Bursa. A recent study, Bilici et al. (2018) analyzed the effects of site factors on performance of a feller-buncher in a Brutian pine stand for the first time in Turkey.

In recent years, feller-bunchers have been effectively used in whole-tree harvesting operations of coniferous stands in Turkey. The main reason behind this trend is that the amount of wooden raw material demand of the private forest industries has increased to such a level that can only be met by fully mechanized harvesting systems (Bilici et al. 2018). The productivity of feller-bunchers depends on many factors such as stand structure, harvesting intensity, terrain characteristics and operator skills (Long et al. 2002, Wang et al. 2004, Visser \& Spinelli 2012, Hiesl \& Benjamin 2013). The time and motion study has been effectively used to estimate the productivity of mechanized harvesting equipment (Öztürk \& Demir 2005, Sabo \& Porsinsky 2005, Zecic et al. 2006, Acar et al. 2010, Akay et al. 2016, Gülci 2020).

In this study, the time and motion technique 
were implemented to estimate the productivity of a feller-buncher used in whole-tree harvesting operation. Time measurements of fellerbuncher work elements (i.e. moving to tree to be cut, cutting the tree, and bunching the tree at the skid trail) were performed in a Maritime pine stand located in the city of Çanakkale in Turkey. The correlations between productivity of feller-buncher and stand parameters (i.e. tree height, DBH, and volume) were also examined. The relationships between productivity and these parameters have been investigated by four regression models in accordance with the success of the models.

\section{Materials and Methods}

\section{Study area}

The study area is located in the Lapseki province of Çanakkale in north-west part of Turkey. The geographical location of the study area is in $40^{\circ} 21^{\prime} 02^{\prime \prime}-40^{\circ} 22^{\prime} 32^{\prime \prime} \mathrm{N}$ and $26^{\circ} 57^{\prime} 35^{\prime \prime}$ - $26^{\circ} 58^{\prime} 40^{\prime \prime}$ E. The whole-tree
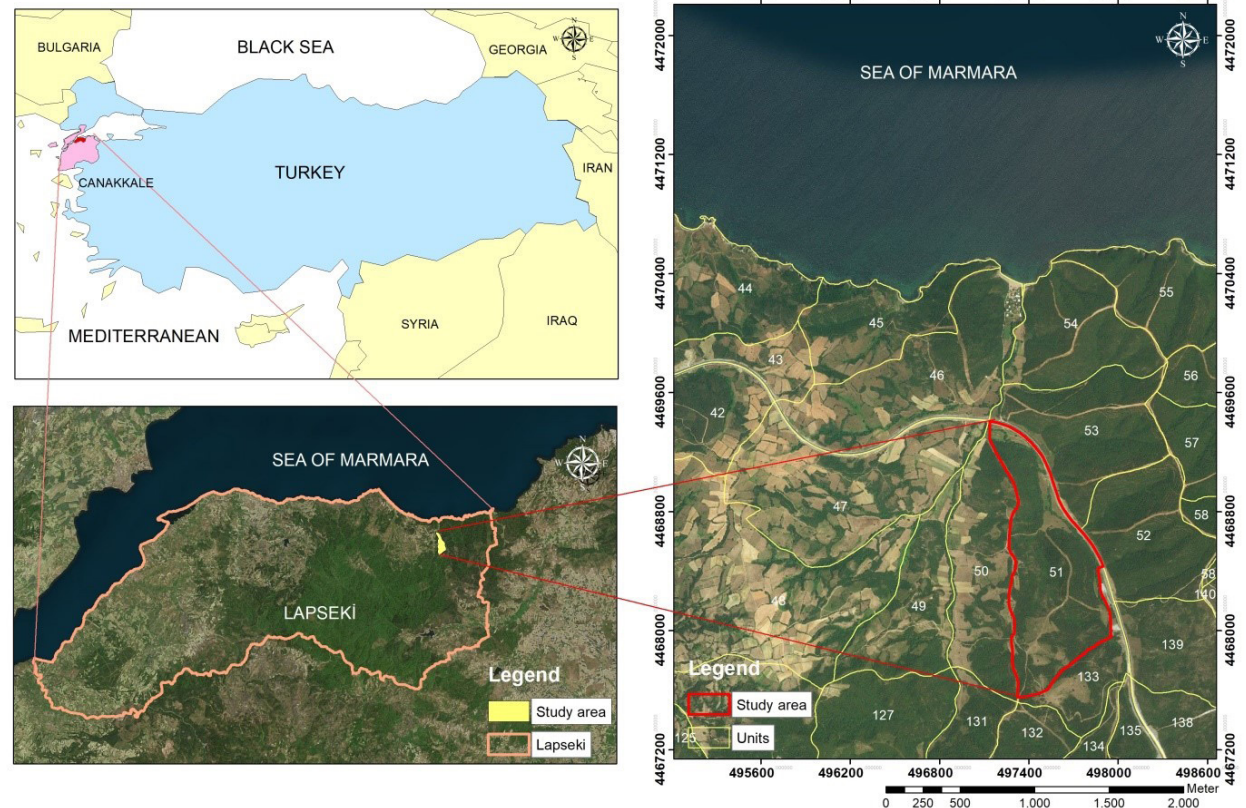

Figure 1 Geographical location of Lapseki Forest Enterprise Chief (FEC) and the compartment numbers of the study area. 
In the field, the tree diameter, tree height, and ground slope were measured by using a caliper and a clinometer. Time measurements were performed by using two "Selex 7064" chronometers. Some technical specifications of the feller-buncher and carrier platform (excavator) are indicated in Table 1.

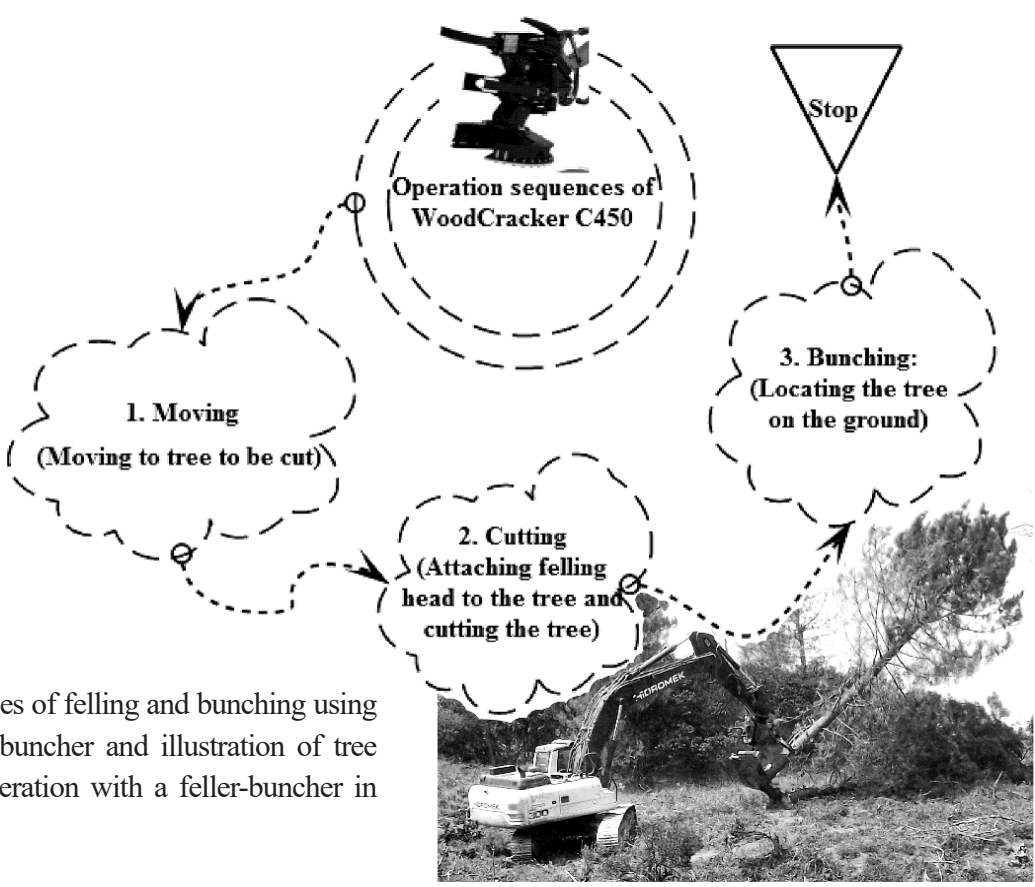

Figure 2 Work stages of felling and bunching using the feller-buncher and illustration of tree felling operation with a feller-buncher in field.

Table 1 Technical specifications of the feller-buncher and carrier platform.

\begin{tabular}{ll}
\hline \multicolumn{1}{c}{ Features of Wood Cracker C450 / Excavator } & Specifications \\
\hline Cutting Diameter (mm) / Number of cylinders & $450 / 6$ \\
Gripper Opening (mm) / Engine volume (cc) & $1600 / 7790$ \\
Diameter of Shears (mm) / Engine power (HP) & $800 / 216$ \\
Weight (Base - Full Equipment) (kg) / Torque (Nm) & $1500-2100 / 940$ \\
Recommended Liter Capacity (lt/min) / Operating weight (kg) & $80-160 / 32600$ \\
Recommended Operating Pressure (Bar) / Boom dimension (m) & $280 / 6.28$ \\
Service Weight Carrier Vehicle (ton) / flow rate of pilot pump (lt/min) & $20-25 / 27$ \\
\hline
\end{tabular}

\section{Statistical analysis}

Firstly, basic average and standard deviation values were computed by using SPSS and R program (R Core Team 2018). Pearson correlation test was used to investigate the relationships between specified factors (tree height, DBH, and volume) and productivity of felling and bunching operation. Tree diameters were divided into four diameter classes including very small $(<20 \mathrm{~cm})$, small $(20-23 \mathrm{~cm})$, medium $(24-27 \mathrm{~cm})$ and large $(>27 \mathrm{~cm})$ diameters. Then, One-Way ANOVA was used to investigate the effects of tree diameter classes on relevant work stages (i.e. cutting time and bunching time) and productivity of the feller-buncher.

After conducting the time and motion study in the field, the productivity of the feller-buncher was computed based on the cycle time and volume of a tree cut per turn. The following formula was used to compute productivity (Eq. 1):

$$
p=\frac{v}{t_{i}} \times 60
$$

Where; $\mathrm{p}$ is the productivity $\left(\mathrm{m}^{3} / \mathrm{h}\right), \mathrm{v}$ is the tree volume $\left(\mathrm{m}^{3}\right)$, ti is the cycle time ( $\left.\mathrm{min}\right)$ and 60 is used to convert time from minute to hour. 


\section{Developing productivity models}

Multiple regression analysis was used to develop the mathematical models of fellerbuncher productivity for whole-tree harvesting. Multiple linear regression model was initially used for assessing the relationship between tree height, $\mathrm{DBH}$, volume and productivity. Diagnostic plots were used to evaluate the success of the prediction model and to develop the model's accuracy. Residuals versus leverage graphic, Q-Q plot and standardized residuals were interpreted and Cook's distance value of the data was examined. By means of standardized residuals by leverage, values were estimated in the modeling of productivity estimation model. Observations that negatively affect the model were removed and the models were re-estimated.

The success of linear and polynomial models was evaluated based on significance of regression coefficients by using the Akaike's information criterion (AIC) (Eq.2) and Bayesian information criterion (BIC) (Eq.3).

$A I C=-2 \log L+2 k$

Where; $L$ is the maximum value of the $\log$ likelihood function and $k$ is the number of regressors of model parameters.

$B I C=-2 \ln L^{i}+k \ln (N)$

Where; $\mathrm{L}^{\mathrm{i}}$ is the maximized value of the likelihood function of the model, and $\mathrm{N}$ is the number of data (observations, measurements or sample size).

Then $\mathrm{R}^{2}$, adjusted $\mathrm{R}^{2}\left(\mathrm{Adj} \mathrm{R}^{2}\right)$, root mean square error (RMSE) and mean absolute error (MAE) were estimated as indicated in Eq. 4-7. In the calculation and visualization of the data, R-packages "pshyc", "broom" and "ggplot2" are preferred (Van den Boogaart \& TolosanaDelgado 2013, Wickham 2016, Revelle 2017, Robinson \& Hayes 2018).

$$
\begin{aligned}
& R^{2}=1-\frac{\sum\left(x_{i}-\hat{x}\right)^{2}}{\sum\left(x_{i}-\bar{x}\right)^{2}} \\
& \operatorname{Adj}^{2}=1-\left[\frac{\left(1-R^{2}\right)(N-1)}{N-k-1}\right] \\
& R M S E=\sqrt{\frac{\sum_{i=1}^{N}\left(x_{i}-\hat{x}\right)^{2}}{N}} \\
& M A E=\frac{1}{n} \sum_{i=1}^{N}\left|x_{i}-\hat{x}\right|
\end{aligned}
$$

Where $\mathrm{x}_{\mathrm{i}}$ is the observed value, $\hat{\mathrm{x}}$ is the predicted value, $\mathrm{R}^{2}$ is defined in the Eq. 4 and $\overline{\mathrm{x}}$ is the mean value of $\mathrm{x}_{\mathrm{i}}$.

\section{Results}

In the harvesting unit, the average tree diameter, height, and volume were $23.13 \mathrm{~cm}$, $14.8 \mathrm{~m}$ and 0.38 $\mathrm{m}^{3}$, respectively. During harvesting, the proportion of work elements (moving, cutting and bunching time) was calculated for the Wood Cracker C450 model fellerbuncher.
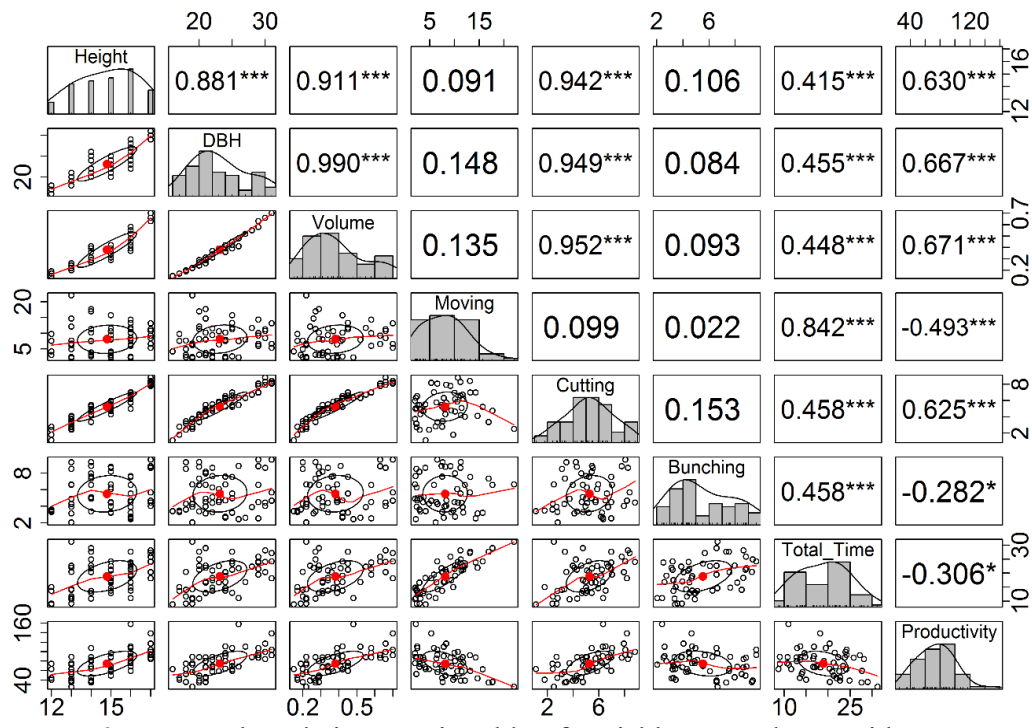

Figure 3 The relation matrix table of variables accordance with Pearson's $r$ correlations (significance levels are *: 0.05 and ***: 0.001) 
The most time-consuming work element was moving time $(60 \%)$, followed by cutting time (29\%) and bunching time $(11 \%)$. The results indicated that the average productivity of the feller-buncher was estimated as $74.96 \mathrm{~m}^{3} / \mathrm{h}$ which is much higher than the productivity of conventional tree cutting methods (Câmpu \& Ciubotaru 2017, Aruga et al. 2019, Ghaffariyan 2021). Table 2 shows the descriptive statistics of all variables.

The correlation between the specified stand parameters (i.e. tree height, $\mathrm{DBH}$, and volume) and productivity of the feller-buncher was determined by using Pearson correlation test. It was found that there was a strong positive association between productivity and tree height $(\mathrm{r}=0.63), \mathrm{DBH}(\mathrm{r}=0.67)$, volume $(\mathrm{r}=0.67)$. All other correlation values and plots can be seen in Figure 3.

The effects of tree diameter classes on relevant work elements (i.e. moving, cutting and bunching time) and productivity were investigated by using One-Way ANOVA analysis. The differences between the average values of these variables were evaluated by using Duncan's multiple range test (Table 3). Four different $\mathrm{DBH}$ classes were generated as A (16-19 cm), B $(20-23 \mathrm{~cm}), \mathrm{C}(24-27 \mathrm{~cm})$ and D $(28-31 \mathrm{~cm})$. Furthermore, considering significance values of Levene statistic $(p>0.05)$ for test of homogeneity of variances, there were not significant differences between variances of groups. Statistical results indicated that diameter classes caused considerable differences on moving time, cutting time, bunching time, and productivity (Table 3 ).
It was found that the average cutting time increased from smaller to larger diameter trees. Very small diameter class resulted in the lowest effect $(2.69 \pm 0.72 \mathrm{~s})$ on cutting time, while large diameter class showed greatest effect $(7.76 \pm 0.68 \mathrm{~s})$ on cutting time. On the other hand, the effects of diameter classes on bunching time were relatively insignificant. However, the lowest bunching time still occurred at the very small diameter class $(4.79 \pm 2.20 \mathrm{~s})$, while the highest occurred at the large diameter class $(6.07 \pm 2.49 \mathrm{~s})$.

The results indicated that the average productivity increased from the very small diameter class to the large diameter class. In what regards the effects on productivity, very small and small diameter classes $\left(57.73 \pm 18 \mathrm{~m}^{3} / \mathrm{h}\right.$ and $63.19 \pm 19 \mathrm{~m}^{3} / \mathrm{h}$, respectively) were in the same group (A), while medium and large diameter classes $\left(88.80 \pm 28 \mathrm{~m}^{3} / \mathrm{h}\right.$ and $99.72 \pm 15 \mathrm{~m}^{3} / \mathrm{h}$, respectively) were in the other group (B).

\section{Evaluation of model diagnostics}

In this study, tree diameter, tree height and volume were considered to investigate their effects on productivity models. Three independent variables used in the model were examined for sixty measurements. The productivity model initially explained $45 \%$ of the variation through a linear model. However, according to the diagnosis of research results applied to the linear model, it was determined that there are high residual values negatively affecting the model. In addition, the fitted line

Table 2 Descriptive statistics of field measurement, and productivity calculation.

\begin{tabular}{llrrrrrrr}
\hline & Height $(\mathrm{m})$ & $\begin{array}{c}\text { DBH } \\
(\mathrm{cm})\end{array}$ & $\begin{array}{c}\text { Volume } \\
\left(\mathrm{m}^{3}\right)\end{array}$ & $\begin{array}{r}\text { Moving } \\
\text { time }(\mathrm{s})\end{array}$ & $\begin{array}{r}\text { Cutting } \\
\text { time }(\mathrm{s})\end{array}$ & $\begin{array}{r}\text { Bunching } \\
\text { time }(\mathrm{s})\end{array}$ & $\begin{array}{c}\text { Total time } \\
(\mathrm{s})\end{array}$ & $\begin{array}{c}\text { Productivity } \\
\left(\mathrm{m}^{3} / \mathrm{h}\right)\end{array}$ \\
\hline $\mathrm{N}$ & 60 & 60 & 60 & 60 & 60 & 60 & 60 & 60 \\
& 14.80 & 23.13 & 0.38 & 8.10 & 5.26 & 5.51 & 18.86 & 74.96 \\
Mean & Median & 15.00 & 22.00 & 0.33 & 7.85 & 5.15 & 4.80 & 19.27 \\
& STD. & 1.49 & 4.09 & 0.15 & 4.50 & 1.79 & 2.20 & 5.62 \\
Min. & 12 & 16 & 0.15 & 2.04 & 1.13 & 2.04 & 8.72 & 25.73 \\
Max. & 17 & 31 & 0.70 & 22.04 & 8.82 & 9.61 & 84.50 & 158.40 \\
\hline
\end{tabular}


Table 3 One-Way ANOVA and post hoc multiple comparisons analysis results in represented class for work stages and productivity.

\begin{tabular}{llrrrrr}
\hline & $\begin{array}{l}\text { DBH } \\
\text { Classes }\end{array}$ & N & $\begin{array}{c}\text { Mean } \pm \text { Std. } \\
\text { (second) }\end{array}$ & $\begin{array}{r}\text { Duncan } \\
\text { Analysis }\end{array}$ & Minimum & Maximum \\
\hline \multirow{5}{*}{ Cutting } & $16-19 \mathrm{~cm}$ & 12 & $2.69 \pm 0.72$ & $\mathrm{~A}$ & 1.13 & 3.73 \\
$\mathrm{p}=0.00<0.05$ & $20-23 \mathrm{~cm}$ & 23 & $4.83 \pm 0.62$ & $\mathrm{~B}$ & 3.37 & 5.88 \\
& $24-27 \mathrm{~cm}$ & 13 & $6.06 \pm 0.55$ & $\mathrm{C}$ & 5.21 & 6.97 \\
& $28-31 \mathrm{~cm}$ & 12 & $7.76 \pm 0.68$ & $\mathrm{D}$ & 6.71 & 8.82 \\
& Average & 60 & $5.25 \pm 1.79$ & & 1.13 & 8.82 \\
& 17 & 31 & 0.70 & 22.04 & 8.82 & 9.61 \\
\hline \multirow{5}{*}{ Bunching } & $16-19 \mathrm{~cm}$ & 12 & $4.79 \pm 2.20$ & $\mathrm{~A}$ & 2.04 & 9.28 \\
$\mathrm{p}=0.00<0.05$ & $20-23 \mathrm{~cm}$ & 23 & $5.97 \pm 1.94$ & $\mathrm{~A}$ & 3.14 & 9.33 \\
& $24-27 \mathrm{~cm}$ & 13 & $4.81 \pm 2.23$ & $\mathrm{~A}$ & 2.42 & 8.86 \\
& $28-31 \mathrm{~cm}$ & 12 & $6.07 \pm 2.49$ & $\mathrm{~A}$ & 2.52 & 9.61 \\
& Average & 60 & $5.50 \pm 2.20$ & & 2.04 & 9.61 \\
\hline \multirow{5}{*}{ Productivity } & $16-19 \mathrm{~cm}$ & 12 & $57.73 \pm 18$ & $\mathrm{~A}$ & 25.73 & 88.81 \\
$\mathrm{p}=0.00<0.05$ & $20-23 \mathrm{~cm}$ & 23 & $63.19 \pm 19$ & $\mathrm{~A}$ & 34.68 & 89.03 \\
& $24-27 \mathrm{~cm}$ & 13 & $88.80 \pm 28$ & $\mathrm{~B}$ & 58.89 & 158.40 \\
& $28-31 \mathrm{~cm}$ & 12 & $99.72 \pm 15$ & $\mathrm{~B}$ & 84.50 & 138.57 \\
& Average & 60 & $74.95 \pm 26$ & & 25.73 & 158.40 \\
\hline
\end{tabular}

created for residuals revealed the assumption that a polynomial approach may be appropriate for data fitting (Figure 4).

In other words, residuals and the fitted plotmodel revealed that the model is not an
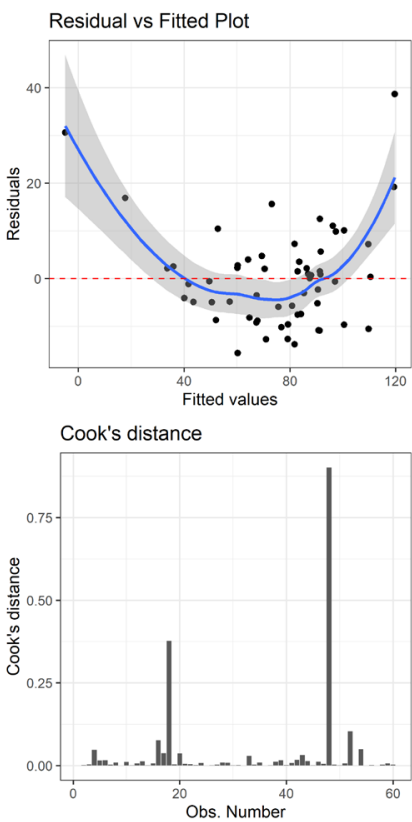

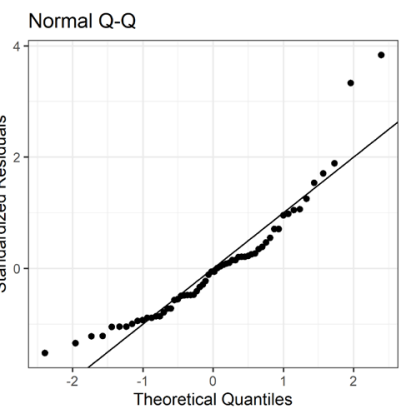

Residual vs Leverage Plot

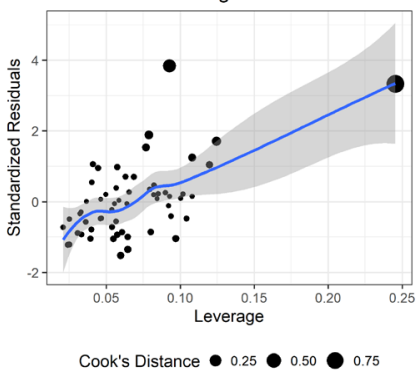

exact linear relation. Cook's distance and leverage diagnosis tests showed some outliers, which were far away of the independent variable values of observation. In the graphical analysis of Cook's distance (CD), some
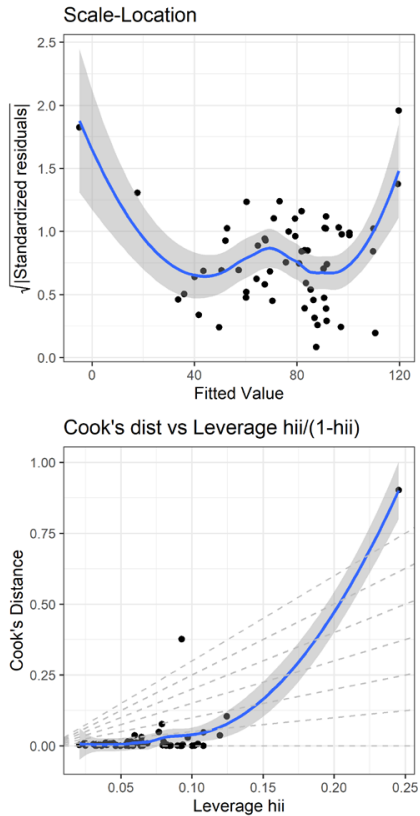

Figure 4 Diagnosis plots for the analysis of productivity estimation model. 
observations (i.e. CD Value >0.25) had a negative effect on the model. These influential observation points (three measured data) were excluded from the model (Figure 4). Besides, the fitted plot as shown in Figure 4, tends to be a polynomial instead of a linear model; to improve the reliability of the model, a polynomial interpolation technique was applied and tested.

\section{Comparison and assessment of prediction models}

Independent variables obtained from engineering studies may not present a linearity with dependent variables. For this reason, linear models may need interpolation with the help of diagnostic analysis, making the success of model's estimation more realistic. Within the scope of the study, after interpreting diagnostic plots for the linear model, four different models were tested and estimated (Figure 5).
Model 1, in which all observation points were included, was estimated by linear regression (Figure 5a). Model 2 was analyzed by (secondorder) polynomial regression by including all the observation points (Figure 5b). Model 3 was analyzed with the help of linear regression by removing observation points that negatively affected the model (Figure 5c). For model 4, observation points that negatively affected the model's success were removed and a (secondorder) polynomial function was analyzed with the help of regression (Figure 5d). Therefore, all four models can be used to explain the productivity of the feller-buncher.

AIC and BIC values were used to select the most efficient and preferable estimation model. Errors of the observation results obtained as a result of engineering studies are widely evaluated with RMSE and MAE. Therefore, $\mathrm{AIC}, \mathrm{BIC}, \mathrm{RMSE}, \mathrm{MAE}, \mathrm{R}^{2}$ and $\mathrm{Adj}^{2}$ were used as criteria to compare the four models. When considering the state of the AIC and BIC values of
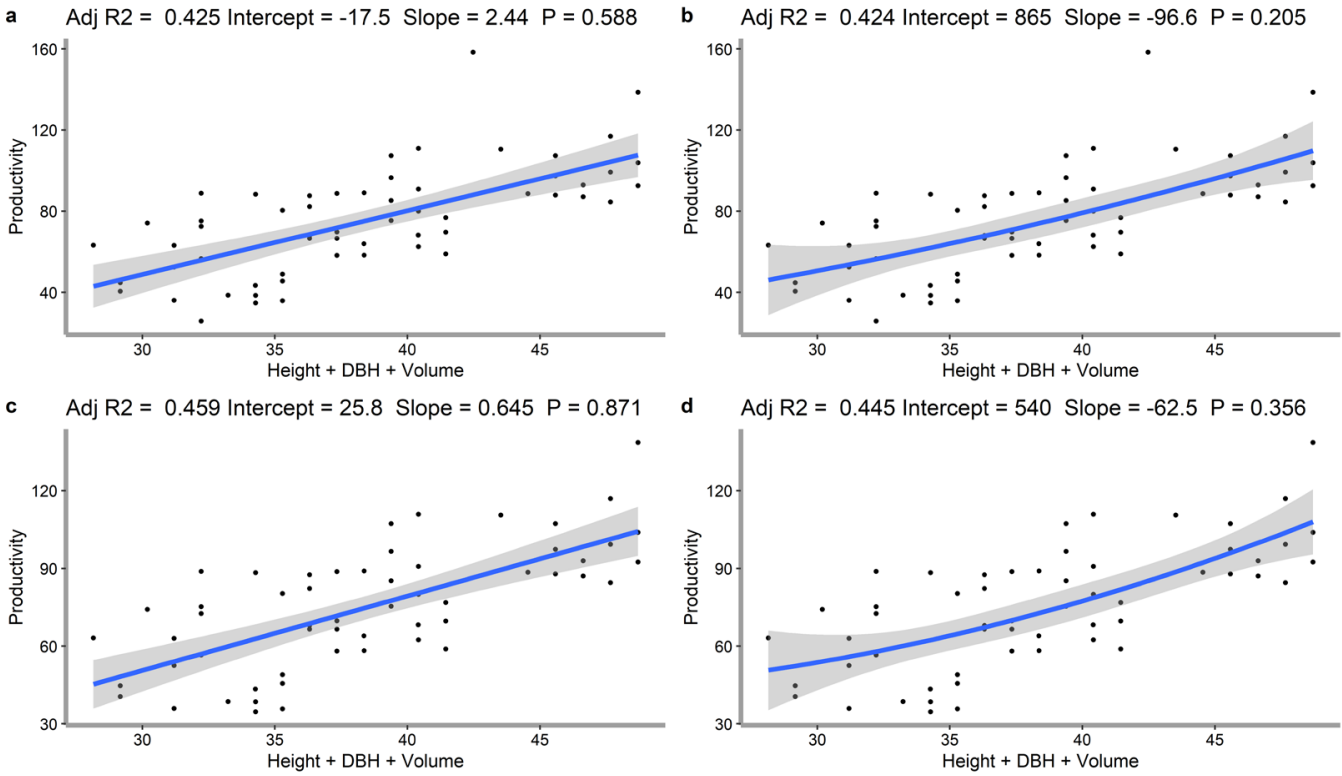

Figure 5 Linear and polynomial regression fitted plots for productivity estimation model of timber harvesting. Fitted plots of multiple linear regression with all observation points (a), and multiple (second-order) polynomial regression with all observation points (b). Fitted plots of multiple linear regression with excluded observation points (c), and multiple (second-order) polynomial regression with excluded observation points (d). 
the estimation model and the interpolation model, the reliability of the interpolation model has tended to increase compared with the reliability of the estimation model. As parametric measures, RMSE and MAE have shown improvements on the error of estimations (Table 4). It was obviously seen that the RMSE and MAE improved after fitting the interpolated models. Furthermore, $\mathrm{R}^{2}$ and $\operatorname{Adj} R^{2}$ improvements were observed after interpolations.

Table 4 Comparison of generated productivity models (Fig. 5). Performance indicators, and coefficients of goodness of fits to estimate productivity for feller-buncher in timber harvesting operation.

\begin{tabular}{|c|c|c|c|c|}
\hline Coefficients & Model 1 & Model 2 & Model 3 & Model 4 \\
\hline Intercept & -17.519 & 25.754 & 864.760 & 540.134 \\
\hline Height & 2.438 & 0.645 & -96.626 & -62.527 \\
\hline Height $^{2}$ & & & 3.957 & 2.768 \\
\hline DBH & 1.616 & 0.118 & -26.508 & -15.339 \\
\hline $\mathrm{DBH}^{2}$ & & & 0.929 & 0.678 \\
\hline Volume & 50.013 & 95.870 & -145.631 & -376.775 \\
\hline Volume $^{2}$ & & & -470.935 & -171.468 \\
\hline \multicolumn{5}{|c|}{ Sensitivity and performance indicators } \\
\hline $\mathrm{R}^{2}$ & 0.45 & 0.49 & 0.48 & 0.50 \\
\hline $\operatorname{Adj}^{2}$ & 0.42 & 0.46 & 0.42 & 0.44 \\
\hline RMSE & 19.19 & 16.64 & 18.69 & 16.37 \\
\hline MAE & 15.48 & 14.08 & 15.07 & 13.78 \\
\hline AIC & 535.00 & 492.00 & 538.00 & 496.00 \\
\hline BIC & 545.00 & 503.00 & 554.00 & 513.00 \\
\hline
\end{tabular}

\section{Discussion}

Statistical analysis revealed that productivity of the feller-buncher varies with the tree height, $\mathrm{DBH}$, and volume. The most time-consuming work element, accounting for $60 \%$ of the time, was moving to the tree (Table 2). Similar studies investigating the productivity of fellerbunchers also stated that moving to the tree to be cut is the most time-consuming work element (Long et al. 2002). The time spent on bunching was the least time-consuming work element since the feller-buncher operator placed the felled trees at the closest convenient location near the skid trail.

The results also indicated that diameter classes significantly affected the time spent on work elements which then reflected on the productivity of the feller-buncher. Previous studies conducted on feller-buncher performance also reported that tree size was the main factor affecting the productivity of felling and bunching operations (Wang et al. 2004, Bilici et al. 2018). Similarly, previous studies also stated that timber volume plays an important role on total time and productivity of feller-bunchers (Visser \& Stampfer 2003, Spinelli et al. 2020).

According to the comprehensive review of Hiesl \& Benjamin (2013) on the productivity of harvesting equipment, the productivity rates can vary due to the harvesting techniques, site and stand parameters, operators and equipment used. However, the results of this study showed strong similarities with the results from other relevant studies in which it was generally reported that productivity of timber harvesting tended to increase as the tree diameter increased (Adebayo et al. 2007). It appears to be consistent with the "piece-volume-law" described and 
explained by Heinaman (2007). Accordingly, the productivity of each work element of the felling and bunching operations increases as the tree diameter increases (Ghaffariyan et al. 2012). However, according to the increase in the size of the work piece, a decrease in productivity can be observed after a certain limit (Visser \& Spinelli 2012). In this study, between the $16-31 \mathrm{~cm} \mathrm{DBH}$ levels, the impact of the work piece size limit on the productivity is not seen. Further research is needed to investigate the optimal productivity model that may focus on DBH greater than $31 \mathrm{~cm}$.

AIC and BIC values belonging to interpolation methods used in the optimization of models (Model 2, 3 and 4) decreased, which resulted in an improvement in the estimation success (Table 4). When the performance of polynomial and linear models is compared, Model 2 and Model 4 estimated more successfully because their sensitivity and performance indicator values were high. On the other hand, Model 4 proved to be the most successful for estimation compared to other models according to the result of RMSE and MAE (Figure 5d). However, Model 2 (Figure $5 b)$ proved to be the most successful for estimation model compared to other models in terms of AdjR2, AIC and BIC value (Table 4). Considering similar examples from 20 years ago, the efficiency of feller-bunchers in timber production has increased with the developments in forest machine technology. Furthermore, the time study analysis with the help of software can easily find the best regressors for highly mechanized forest equipment (Mușat et al. 2015). It can be suggested that mechanized harvesting with a feller-buncher can be very productive; however further studies on harvesting productivity of feller-bunchers are required for optimum selection of the carrier platform and equipment. Also, due to the technological and automation systems developed in harvesting machinery, forest engineers can easily adapt to the Internet of Things (IoT) for operational planning and logistics (Spinelli et al. 2019) according to the precision forestry approach. Further studies in advanced measuring techniques with various sensor-based or manually measured data can consider using polynomial regression instead of linear regression (Kemmerer \& Labelle 2020). Therefore, regressors should be tested and experienced for further analysis in productivity of harvesting machinery to select the best productivity model.

\section{Conclusions}

In recent years, fully mechanized harvesting systems have been used by logging contractors in some regions of Turkey where terrain conditions and stand characteristics are proper for them. A time and motion study was implemented to estimate the productivity of whole-tree harvesting with a feller-buncher. Time measurements of feller-buncher work elements (i.e. moving to tree to be cut, felling and bunching the tree at the skid trail) were carried out in a Maritime pine stand located in the city of Çanakkale in north-western Turkey. The results indicated that the average productivity of the feller-buncher ( $\sim 75 \mathrm{~m}^{3} /$ hour $)$ was much higher than the average productivity of the motor manual method traditionally practiced. The results also indicated that diameter classes significantly affect the time spent on work elements, therefore affecting the productivity of the feller-buncher. The productivity of timber harvesting equipment can be analyzed using polynomial regression. Considering the calculated measurement error parameters, second-degree polynomial models improve the model performance for conventionally fieldmeasured data. The mechanized harvesting method can be very productive, but it should be well planned and the right machine should be selected in order to maximize productivity and minimize adverse impacts. 


\section{References}

Abbas D., Handler R., Hartsough B., Dykstra D., Lautala P., Hembroff L., 2014. A survey analysis of forest harvesting and transportation operations in Michigan. Croatian Journal of Forest Engineering 35(2): 179-192.

Acar H.H., Ünver S., Özkaya M.S., 2010. Investigation on efficiency of the harvesting machineries at Artvin Regional Directorate of Forestry. Artvin Coruh University, Journal of Forestry Faculty 11(2): 12-19.

Acuna M., Sessions J., Zamora R., Boston K., Brown M., Ghaffariyan M. R., 2019. Methods to manage and optimize forest biomass supply chains: A review. Current Forestry Reports, 5(3), 124-141. https://doi. org/10.1007/s40725-019-00093-4

Adebayo A.B., Han H.S., Johnson L., 2007. Productivity and cost of cut-to-length and whole-tree harvesting in a mixedconifer stand. Forest Products Journal 57(6): 59-69.

Akay A.E., Özkan D., Bilici E., 2016. Assessing productivity and work safety of a mechanized logging operation. The International Forestry Symposium, 7-11 December, Kastamonu, Turkey.

Akay A.E., Sessions J., Serin H., Pak M., Yenilmez N., 2010. Applying optimum bucking method in producing Taurus Fir (Abies cilicica) logs in Mediterranean region of Turkey. Baltic Forestry 16(2): 273-279.

Apăfăian A. I., Proto A. R., Borz S. A., 2017. Performance of a mid-sized harvester-forwarder system in integrated harvesting of sawmill, pulpwood and firewood. Annals of Forest Research 60(2): 227-241. https://doi. org/10.15287/afr.2017.909

Aruga K., Yamada, T., Yamamoto, T., 2019. Comparative analyses of the cycle time, productivity, and cost between 62-and 107-year-old Japanese cypress clearcutting operations using a small-scale cable logging system. Small-scale Forestry 18(2): 279-289. https:// doi.org/10.1007/s11842-018-9412-7

Bilici E., Abbas D., 2018. Performance analysis of a harvester during timber extraction activities in Bursa, Turkey. European Journal of Forest Engineering 4(1): 7-12. https://doi.org/10.33904/ejfe.426171

Bilici E., Akay A.E., Abbas D., 2018. Assessing the effects of site factors on the productivity of a feller buncher: a time and motion analysis. Journal of Forestry Research 30(4): 1471-1478. https://doi.org/10.1007/s11676-0180696-4

Câmpu V. R., Ciubotaru A., 2017. Time consumption and productivity in manual tree felling with a chainsaw-a case study of resinous stands from mountainous areas. Silva Fennica 51(2):1657. https://doi.org/10.14214/ sf.1657

Eker M., Acar H.H., 2006. Operational planning method for timber harvesting. Turkish Journal of Forestry 7(2): 128-140.

Enez K., Aricak B., 2012. Assessment of technical and working conditions of a harvester. Journal of Science and Engineering Special Issue: 108-114.
Erdaş O., Acar H.H., Eker M., 2014. Forest transportation technique. Karadeniz Technical University, Trabzon, 504 p.

Erler J., Purfürst T., Dög M., 2012. Präzise Forstwirtschaft. Fachinstitut für Waldarbeit e. V. Tharandt, Germany, $92 \mathrm{p}$.

Fernandez-Lacruz R., Edlund M., Bergström D., Lindroos O., 2020. Productivity and profitability of harvesting overgrown roadside verges-a Swedish case study. International Journal of Forest Engineering 32:19-28. https://doi.org/10.1080/14942119.2020.1822664

GDF, 2018. Forest Map of Lapseki Forest Enterprise Chief (FEC). General Directorate of Forestry, Turkey.

Ghaffariyan M.R., Acuna M., Kellogg L., 2012. Productivity of roadside processing system in Western Australia. Silva Balcanica 13(1): 49-60.

Ghaffariyan M. R., 2021. Review of studies on motormanual felling productivity in eucalypt stands. Silva Balcanica 22(1): 77-87. https://doi.org/10.3897/ silvabalcanica.22.e58750

Gülci N., 2014. Researches on precision forestry in forest planning. Dissertation (Doctor of philosophy Thesis), Faculty of Forestry, Kahramanmaras Sutcu Imam University, Kahramanmaraş, 264 p. [Turkish]

Gülci N., Yüksel K., Akay A.E., 2017. Productivity assessment of portable hand winch based skidding operation on snow cover. Kastamonu University, Journal of Forestry Faculty 17(1): 124-131.

Gülci S., 2020. Productivity of a farm tractor with single drum winch during whole-tree timber extraction. Šumarski list 144(1-2): 35-42. https://doi.org/10.31298/ sl.144.1-2.4

Heinimann H.R., 2007. Forest operations engineering and management - the ways behind and ahead of a scientific discipline. Croatian Journal of Forest Engineering 28(1): 107-121.

Hiesl P., Benjamin J.G., 2013. Applicability of international harvesting equipment productivity studies in Maine, USA: A literature review. Forests 4(4): 898-921. https:// doi.org/10.3390/f4040898

Kemmerer J., Labelle E. R., 2020. Using harvester data from on-board computers: a review of key findings, opportunities and challenges. European Journal of Forest Research 140:1-17. https://doi.org/10.1007/ s10342-020-01313-4

Long C., Wang J., Mcneel J., Baumgras J., 2002. Production and cost analysis of a feller-buncher in central Appalachian hardwood forest. Council on Forest Engineering Proceedings, 25th Annual Meeting, Forest Engineering Challenges, 16-20 June, Auburn, Alabama.

Mușat E. C., Apăfăian A. I., Ignea G., Ciobanu V. D., Iordache E., Derczeni R. A., ... Borz S. A., 2015. Time expenditure in computer aided time studies implemented for highly mechanized forest equipment. Annals of Forest Research 59(1): 129-144. https://doi. org/10.15287/afr.2015.473

Öztürk T., 2006. Work phases of wood productivity in Turkey. Journal of the Faculty of Forestry Istanbul University 56(2): 109-122. https://doi.org/10.17099/ jffiu.98953 
Öztürk T., Demir M., 2005. Work performance of MB Trac 900 tractor on mountains terrain in Turkey. American Journal of Applied Sciences 2(1): 363-366. https://doi. org/10.3844/ajassp.2005.363.366

R Core Team, 2018. R: A language and environment for statistical computing ( $\mathrm{R}$ version 3.5.2.), R Foundation for Statistical Computing, Vienna, Austria. http:// www.R-project.org/ [accessed on 28.05.2019].

Revelle W.R., 2017. Psych: Procedures for Personality and Psychological Research, version 1.8.12. Northwestern University, Evanston, Illinois, USA.

Robinson D., Hayes A., 2018. broom: Convert Statistical Analysis Objects into Tidy Tibbles, version: 0.5.6.

Sabo A., Poršinsky T., 2005. Skidding of fir roundwood by Timberjack $240 \mathrm{C}$ from selective forests of Gorski Kotar. Croatian Journal of Forest Engineering 26(1): 13-27.

Spinelli R., Visser R., Han H.S., 2019. A Decade of Forest Engineering: Achievements and Future Directions. Forests 10(9): 724. https://doi.org/10.3390/f10090724

Spinelli R., Magagnotti N., Lombardini C., 2020. Lowinvestment fully mechanized harvesting of shortrotation poplar (Populus spp.) plantations. Forests, 11(5):502. https://doi.org/10.3390/f11050502

Swezy C., Bailey J., Chung W., 2021. Linking federal forest restoration with wood utilization: modeling biomass prices and analyzing forest restoration costs in the Northern Sierra Nevada. Energies 14(9): 2696. https://doi.org/10.3390/en14092696
Van den Boogaart K.G., Tolosana-Delgado R., 2013. Analyzing compositional data with R. Berlin: Springer.

Visser R., Spinelli R., 2012. Determining the shape of the productivity function for mechanized felling and felling-processing. Journal of Forest Research 17(5): 397-402. https://doi.org/10.1007/s10310-011-0313-2

Visser R., Stampfer K., 2003. Tree-length system evaluation of second thinning in a loblolly pine plantation. Southern Journal of Applied Forestry 27(2): $77-82$.

Wang J., Long C., Mcneel J., 2004. Production and cost analysis of a feller-buncher and grapple skidder in central Appalachian hardwood forests. Forest Products Journal 54(12): 159-167.

Wickham H., 2016. ggplot2: Elegant Graphics for Data Analysis. New York (NY): Springer.

Zecic Z., Krpan A.P., Vukusic S., 2006. Productivity of C Holder $870 \mathrm{~F}$ tractor with double drum winch Igland 4002 in thinning beech stands. Croatian Journal of Forest Engineering 27(1): 49-57.

Timbal J., Aussenac G., 1996. An overview of ecological and silviculture of indigenous oaks in France. Ann. Sci. For., 53: 649-661.

Weaver G., Spiecker H., 1993. Silviculture of high-quality oaks: questions and future research needs. Ann. Sci. For., 50(6): 531-534. 